\title{
Faktor - Faktor yang Mempengaruhi Permintaan Sayuran Daun Oleh Rumah Makan di Kecamatan Kota Kefamenanu Kabupaten Timor Tengah Utara
}

I Komang Adi Wirawan ${ }^{\mathrm{a}}$ dan Agustinus Nubatonis ${ }^{\mathrm{b}}$

${ }^{a}$ Fakultas Pertanian, Universitas Timor, TTU-NTT, Indonesia. Email: komangawan2580123@gmail.com

${ }^{b}$ Fakultas Pertanian, Universitas Timor, TTU-NTT, Indonesia. Email: agustinusnubatonis74@gmail.com

\section{Article Info}

\section{Article history:}

Received 2 Desember 2018

Received in revised form 10 Januari 2019

Accepted 28 Januari 2019

https://doi.org/10.32938/ag.v4i01.583

Keywords:

Permintaan

Rumah Makan

Sayuran Daun

\section{Pendahuluan}

Peningkatan jumlah penduduk Indonesia memiliki hubungan yang sejalan dengan peningkatan konsumsi sayuran di Indonesia. Frekuensi konsumsi atau makan sayuran di kota - kota besar tidak begitu mengalami penurunan. Hal in karena adanya daya beli konsumsi masyarakat cukup tinggi terhadap sayuran. Padahal seperti produk hortikultura yang lain, sayuran sangat mudah rusak dan membusuk dalam waktu yang relatif singkat sehingga mutunya menurun dan bahkan tidak dapat dikonsumsi sama sekali. Hal ini berarti pasar harus selalu dipasok sayuran segar setiap hari. (Rahadi, dkk., 1995).

Wilayah Kabupaten Timor Tengah Utara (TTU) memiliki luas 2.669,70 $\mathrm{km}^{2}$, yang keseluruhannya secara proporsi hanya 5,6 persen dari luas daratan Provinsi Nusa Tenggara Timur (NTT). Kabupaten Timor Tengah Utara terdir dari 24 kecamatan, 193 desa/kelurahan. Menurut hasil registrasi penduduk 2013 , jumlah penduduk Kabupaten Timor Tengah Utara adalah 240.686 orang yang terdiri dari 119.488 laki - laki dan 121.198 perempuan. Jumlah ini bertambah dari tahun sebelumnya sebesar 6.041 jiwa atau bertambah sebesar 2,57 persen. Sementara Jumlah kepala keluarga pada tahun 2013 yaitu 58.110 dengan rata rata anggota keluarga sebanyak 4 orang. (BPS TTU, 2014).

Kecamatan Kota Kefamenanu dengan jumlah penduduk dan Kepala Keluarga (KK) dari tahun 2011 - 2014 yakni dengan rincian tahun 2011 jumlah penduduk 39.546 dengan jumlah KK 8.381, pada tahun 2012 jumlah penduduk mengalami penurunan yakni 39.190 dengan jumlah KK 8.525 aspek yang berpengaruh pada jumlah penduduk tahun 2012 yakni perpindahan penduduk dan peningkatan jumlah kematian, tahun 2013 jumlah penduduk 41.848 dengan jumlah KK 8.613, tahun 2014 jumlah penduduk 42.321 jiwa dengan jumlah KK 8.625. (BPS TTU, $2012-2014$ ).

Tamu atau pengunjung pada Rumah makan di Kecamatan Kota Kefamenanu selain berasal dari penduduk lokal juga berasal dari luar daerah, yang mana tujuan mereka untuk rekreasi, wisata kuliner, ataupun hanya ingin mendapatkan makanan cepat saji.

Kecamatan Kota Kefamenanu sebagai salah satu kecamatan yang berada di Kabupaten Timor Tengah Utara memiliki jumlah masyarakat yang relati banyak dengan keanekaragaman olahan sayuran yang tersedia pada rumah makan untuk dikonsumsi, faktor - faktor yang mempengaruhi rumah makan dalam memilih produk sayuran antara lain pengeluaran pembelian sayuran daun, pengeluaran sayuran pengganti yang mempunyai kaitan erat dengan barang tersebut, jumlah menu olahan, jumlah tamu/pembeli, jumlah tamu pada event (acara).

\section{Metode}

Sayur daun merupakan sayuran yang banyak dikonsumsi oleh masyaraka tingkat atas, menengah, dan bawah. Sehingga sayuran ini banyak dijumpai di pasar kota dan di tempat - tempat pengolahan makanan cepat saji salah satunya adalah rumah makan. Permintaan konsumen sebagian besar didominasi akan produk sayuran, sehingga faktor yang mempengaruhi yakni : pengeluaran pembelian sayuran daun, pengeluaran pembelian sayuran pengganti, jumlah menu olahan, jumlah tamu, dan jumlah tamu pada event, menjadi faktor yang kuat untuk mempengaruhi permintaan oleh rumah makan dalam melakukan pengambilan keputusan untuk membeli sayur daun.

Konsumen dalam hal ini adalah setiap orang pemakai barang dan atau jasa yang tersedia dalam masyarakat, baik bagi kepentingan diri sendiri, keluarga orang lain, maupun makhluk hidup lain dan tidak untuk diperdagangkan. Penelitian dilaksanakan di Kecamatan Kota Kefamenanu, Kabupaten Timo Tengah Utara pada bulan Januari sampai November 2017 sampai selesai. Metode pengumpulan data primer dilakukan secara survei melalui teknik wawancara berdasarkan daftar pertanyaan (kuesioner) yang sudah di sediakan dan juga dilakukan dengan metode observasi atau pengamatan, sedangkan data sekunder diperoleh dari instansi - instansi terkait dan buku - buku penunjang lainnya. Metode penarikan sampel dilakukan dengan metode incidental sampling adalah teknik yang dilakukan secara kebetulan dalam menentukan sampel. Dimana artinya penarikan sampel didasarkan atas pemikiran bahwa keseluruhan unit populasi memiliki kesempatan yang sama untuk dijadikan sampel (Bungin, 2008)

Data dikumpulkan dan ditabulasi, selanjutnya dianalisis sesuai dengan hipotesa yang akan di uji. Hipotesis di uji dengan menggunakan analisis regres linier berganda. Data yang dibutuhkan adalah jumlah permintaan sayuran, pengeluaran pembelian sayur daun, pengeluaran pembelian sayuran pengganti, jumlah menu olahan, jumlah tamu/pembeli, dan jumlah tamu pada event, sehingga modelnya menjadi :

\section{$Y=\beta o+\beta_{1} X_{1}+\beta_{2} X_{2}+\beta_{3} X_{3}+\beta_{4} X_{4}+\beta_{5} X_{5}+e$}

Keterangan :

Bo $\quad=$ Konstanta.

$\beta_{1}-\beta_{5} \quad=$ Koefisien Regresi.

$\mathrm{X}_{1} \quad=$ Pengeluaran pembelian sayur daun $(\mathrm{Rp} / \mathrm{bln})$.

$\mathrm{X}_{2} \quad=$ Pengeluaran pembelian sayuran pengganti $(\mathrm{Rp} / \mathrm{bln})$.

$\mathrm{X}_{3} \quad=$ Jumlah menu olahan

$\mathrm{X}_{4} \quad=$ Jumlah tamu/pembeli (orang).

$\mathrm{X}_{5} \quad=$ Jumlah tamu pada event (orang)

e $\quad=$ Error

Selanjutnya untuk menguji ada tindaknya pengaruh yang nyata secara simultan (bersama-sama) digunakan uji " $F$ " dengan formulasi sebagai berikut:

$$
F_{\text {hit }}=\frac{\text { rata }- \text { rata kuadrat regresi }}{\text { rata }- \text { rata kuadrat residu }}
$$

Hipotesis yang diuji :

$\mathrm{H}_{0}: \sum \mathrm{b}_{\mathrm{i}}=0$

$\mathrm{H}_{\mathrm{a}}: \sum \mathrm{b} \neq 0$

Pengambilan keputusan : jika $\mathrm{f}_{\text {hitung }} \leq \mathrm{t}_{\text {tabel }}$ maka $\mathrm{H}_{\mathrm{O}}$ terima dan $\mathrm{H}_{\mathrm{a}}$ ditolak artinya tidak terdapat pengaruh yang nyata secara bersama-sama dari semua faktor $\left(\mathrm{X}_{\mathrm{i}}\right)$ terhadap Jumlah Permintaan Sayuran (Y) sedangkan bilamana $\mathrm{f}_{\text {hitung }} \geq \mathrm{f}_{\text {tabel }}$ maka tolak $H_{o}$ artinya minimal salah satu variabel babas $\left(\mathrm{X}_{\mathrm{i}}\right)$ berpengaruh nyata terhadap Jumlah Permintaan Sayuran (Y).

Setelah melihat uji f maka dilakukan uji t untuk mengetahui pengaruh parsial dari masing - masing variabel bebas terhadap variabel terikat dengan menggunakan persamaan berikut ini :

$$
T=\frac{b_{i}}{S e}
$$

Dimana :

$\mathrm{T} \quad: \mathrm{t}_{\text {hitung }}$

bi : koefisien regresi

se(bi) : simpangan baku (Gujarati, 2003)

Hipotesis yang diuji :

$\mathrm{H}_{\mathrm{o}}: \beta_{\mathrm{i}}=0$

$\mathrm{H}_{\mathrm{a}}: \beta_{\mathrm{i}} \neq 0$

Kaidah pengambilan keputusan jika $\mathrm{t}_{\text {hitung }} \geq \mathrm{t}_{\text {tabel }}$ maka $\mathrm{H}_{0}$ ditolak artinya faktor $\mathrm{X}_{\mathrm{i}}$ berpengaruh signifikan terhadap variabel $\mathrm{Y}$ dan sebaliknya jika $\mathrm{t}_{\text {hitung }} \leq \mathrm{t}_{\text {tabel }}$ maka $\mathrm{H}_{\mathrm{o}}$ diterima artinya faktor $\mathrm{X}_{\mathrm{i}}$ berpengaruh tidak signifikan terhadap variabe Y. Analisis regresi linier berganda digunakan oleh peneliti, bila peneliti bermaksud meramalkan bagaimana keadaan (naik turunnya) variabel dependen (kriterium), bila dua atau lebih variabel independen di naik turunkan nilainya Jadi analisis regresi linier berganda akan dilakukan bila jumlah variabe independennya minimal 2 (Sugiyono, 2006) 


\section{Hasil dan Pembahasan}

\subsection{Gambaran Umum Lokasi Penelitian}

Kecamatan Kota Kefamenanu yakni dengan luas wilayah $74 \mathrm{~km}^{2}$ atau 2,77 persen dari luas daerah Kabupaten Timor Tengah Utara dengan letak wilayah dengan batas - batas wilayah administratif yaitu; bagian utara berbatasan dengan Kecamatan Miomaffo Timur dan Kecamatan Insana Barat, bagian selatan berbatasan dengan Kecamatan Bikomi Selatan, bagian timur berbatasan dengan Kecamatan Insana Barat, bagian barat berbatasan dengan Kecamatan Bikomi Selatan dan Bikomi Tengah.

\section{Penduduk}

Penduduk merupakan modal dasar pembangunan sekaligus sebagai pelaku utama dan pengguna hasil pembangunan. Berdasarkan Registrasi Penduduk akhir tahun 2014 jumlah penduduk Kecamatan Kota Kefamenanu adalah sebanyak 42.321 jiwa yang terdiri atas penduduk Laki-laki sebanyak 21.190 jiwa dan Perempuan sebanyak 21.131 jiwa, dengan jumlah penduduk terbanyak di Kecamatan Kota Kefamenanu adalah Kelurahan Kefamenanu Selatan sebanyak 9.731 jiwa dan jumlah penduduk terendah adalah kelurahan Kefamenanu Utara 2.588 jiwa. Untuk perincian jumlah penduduk dan luas wilayah dapat dilihat pada tabel 1.

Tabel 1. Jumlah Penduduk, Rumah Tangga, Luas Wilayah, Kepadatan Penduduk dan Kepadatan Rumah Tangga menurut Kelurahan Tahun 2014.

\begin{tabular}{lccccc}
\hline Kelurahan & $\begin{array}{c}\text { Jumlah } \\
\text { penduduk }\end{array}$ & $\begin{array}{c}\text { Jumlah } \\
\text { rumah } \\
\text { tangga }\end{array}$ & $\begin{array}{c}\text { Luas } \\
\text { wilayah } \\
\text { (km })\end{array}$ & $\begin{array}{c}\text { Kepadatan } \\
\text { rumah } \\
\text { tangga } \\
\text { (Jiwa) }\end{array}$ & $\begin{array}{c}\text { Kepadatan } \\
\text { penduduk } \\
\text { per km } \\
\text { (jiwa) }\end{array}$ \\
\hline \multicolumn{1}{c}{$(1)$} & $(2)$ & $(3)$ & $(4)$ & $(5)$ & $(6)$ \\
\hline 1. Maubeli & 4708 & 1015 & 4,00 & 4,64 & 1177 \\
2. Sasi & 3353 & 701 & 6,00 & 4,78 & 559 \\
3. Tubuhue & 4563 & 994 & 12,00 & 4,59 & 380 \\
4. Kefa Selatan & 9731 & 1847 & 7,00 & 5,27 & 1390 \\
5. Benpasi & 5604 & 1037 & 6,00 & 5,40 & 934 \\
6. Bansone & 3371 & 693 & 11,00 & 4,86 & 306 \\
7. Kefa Tengah & 5794 & 1190 & 9,00 & 4,87 & 644 \\
8. Aplasi & 2609 & 575 & 7,00 & 4,54 & 373 \\
9. Kefa Utara & 2588 & 561 & 12,00 & 4,61 & 216 \\
\hline \multicolumn{1}{c}{ Total } & $\mathbf{4 2 . 3 2 1}$ & $\mathbf{8 . 6 1 3}$ & $\mathbf{7 4 , 0 0}$ & $\mathbf{4 , 9 1}$ & $\mathbf{5 7 2}$ \\
\hline S4
\end{tabular}

Sumber : Badan Pusat Statistik (2018)

\section{Tingkat Pendidikan}

Salah satu faktor utama keberhasilan pembangunan di suatu negara adalah tersedianya cukup sumber daya manusia (SDM) yang berkualitas. Salah satu indikator yang dapat digunakan untuk melihat keberhasilan bidang pendidikan adalah tingkat buta huruf. Makin rendah persentase penduduk yang buta huruf menunjukkan keberhasilan program pendidikan, sebaliknya jika semakin tinggi persentase penduduk yang buta huruf mengidentifikasikan kurang berhasilnya program pendidikan. Pencapaian kemajuan dalam bidang pendidikan dapat ditunjang dengan ketersediaan sarana pendidikan, guru dan siswa.

Kecamatan Kota Kefamenanu pada Tahun ajaran 2014/2015 terdapat 24 SD yang terbagi atas 14 SD Negeri dan 10 SD Swasta. Terdapat juga 6 SLTP Negeri dan 6 SLTP Swasta. Untuk SMA ada 8 Sekolah dengan 3 SMA Negeri dan 5 SMA Swasta, sedangkan untuk SMK terdapat 1 sekolah SMK Negeri dan SMK Swasta.

Tabel 2. Jumlah SD, SLTP, SMK/SLTA, PT/Akademi Negeri/Swasta di Kecamatan Kota Kefamenanu Tahun Ajaran 2014/2015.

\begin{tabular}{cc}
\hline Tingkat Sekolah & Negeri/ Swasta \\
\hline$(1)$ & $(2)$ \\
\hline SD & 24 \\
SLTP & 12 \\
SLTA & 8 \\
PT/Akademi & 1 \\
\hline
\end{tabular}

\section{Sumber : Badan Pusat Statistik Diolah (2018)}

\subsection{Karakteristik Responden}

\section{Umur Responden}

Salah satu yang menentukan produktivitas kerja adalah umur. Pada saat umur kurang dari 15 tahun biasanya berada pada usia sekolah sehingga belum termasuk dalam angkatan kerja. Selanjutnya pada usia lebih dari 55 tahun merupakan usia kurang produktif karena kurang mampu lagi melakukan aktivitas yang membutuhkan tenaga yang besar pada usia produktif, dengan demikian kualitas dan produktivitas kerja mengalami penurunan. Selanjutnya pada usia yang kurang produktif berdampak pada tingkat kecakapan kerja yang mulai menurun. Faktor lain yang juga berpengaruh terhadap produktivitas yaitu tingkat pendidikan, keterampilan, kesehatan dan sebagainya. Oleh karena itu, untuk mendukung peningkatan produktivitas diperlukan upaya - upaya peningkatan sumber daya manusia. Berdasarkan hasil penelitian kisaran umur responden. Klasifikasi umur responden dapat dilihat pada tabel 3.

Berdasarkan analisis data primer (table 3) diketahui bahwa responden rumah makan yang diklasifikasikan menurut umur terbanyak pada kisaran 26 35 tahun dengan total 5 orang (36\%). Sedangkan responden rumah makan yang paling sedikit berada pada kisaran umur $56-65$ dengan total keseluruhan 2 Orang (14\%).

\section{Pendidikan}

Semakin tinggi tingkat pendidikan maka produktivitas kerja semakin meningkat, karena tingkat pendidikan dapat merubah pola hidup serta pola pikir. Bag responden, pendidikan dan pengalaman mempunyai pengaruh besar dalam usaha ke depannya. Pendidikan responden rumah makan terperinci dan disajikan dalam tabel 4.

Tabel 3. Klasifikasi umur responden rumah makan di Kecamatan Kota Kefamenanu, Tahun 2017.

\begin{tabular}{cccc}
\hline No. & Umur & Jumlah $(\boldsymbol{\Sigma})$ & Persentase (\%) \\
\hline 1 & $26-35$ & 5 & 36 \\
2 & $36-45$ & 3 & 21 \\
3 & $46-55$ & 4 & 29 \\
4 & $56-65$ & 2 & 14 \\
\hline \multicolumn{2}{r}{ Total } & $\mathbf{1 4}$ & $\mathbf{1 0 0}$
\end{tabular}

Sumber : Analisis Data Primer (2017)

Tabel 4. Klasifikasi Tingkat pendidikan responden rumah makan di Kec. Kota Kefamenanu, Tahun 2017.

\begin{tabular}{cccc}
\hline No. & Pendidikan & Jumlah $(\boldsymbol{\Sigma})$ & Persentase (\%) \\
\hline 1 & SD & 2 & 14 \\
2 & SMP & 1 & 7 \\
3 & SMA & 11 & 79 \\
\hline & Total & $\mathbf{1 4}$ & $\mathbf{1 0 0}$ \\
\hline
\end{tabular}

Sumber : Analisis Data Primer (2017)

Berdasarkan analisis data primer (table 4) diketahui bahwa responden rumah makan yang diklasifikasikan menurut tingkat pendidikan terbanyak pada Sekolah Menengah Atas (SMA) dengan total 11 orang dengan persentase (79\%) dari jumlah keseluruhan. Sedangkan tingkat pendidikan responden rumah makan yang paling sedikit berada pada Sekolah Menengah Pertama (SMP) dengan total 1 Orang (7\%). Pada tingkat pendidikan Sekolah Dasar (SD) yakni dengan total 2 orang $(14 \%)$.

\section{Jumlah Tanggungan Keluarga}

Jumlah anggota keluarga yang menjadi tanggungan dari rumah tangga tersebut, baik itu saudara kandung maupun saudara bukan kandung yang tinggal satu rumah. Meskipun peningkatan penghasilan digunakan untuk menambah jumlah anaknya, akan tetapi lebih baik peningkatan penghasilan digunakan untuk menambah kualitas anaknya melalui pendidikan. Salah satu usaha yang dijalankan pedagang untuk memenuhi kebutuhan keluarga adalah dengan memasarkan barang dagangannya. Masing - masing responden memiliki jumlah tanggungan keluarga yang sangat bervariasi. Untuk lebih jelas dapat dilihat pada tabel 5 .

Tabel 5. Klasifikasi jumlah tanggungan keluarga rumah makan di Kec. Kota Kefamenanu, Tahun 2017.

\begin{tabular}{cccc}
\hline No. & Jmlh. Tanggungan Keluarga & Jmlh. $(\boldsymbol{\Sigma})$ & Persentase (\%) \\
\hline 1 & $\leq 2-3$ & 6 & 43 \\
2 & $4-6$ & 6 & 43 \\
3 & $7-9$ & 2 & 14 \\
\hline & Total & $\mathbf{1 4}$ & $\mathbf{1 0 0}$ \\
\hline
\end{tabular}

Sumber : Analisis Data Primer (2017)

Berdasarkan analisis data primer (table 5) diketahui bahwa responden terbanyak berada pada kisaran jumlah tanggungan keluarga $\leq 2-3$ dan 4 - 6 orang, dengan total keseluruhan $43 \%$ dan jumlah tanggungan keluarga paling sedikit dengan jumlah tanggungan 7 - 9 orang, dengan total persentase $14 \%$.

\section{Pengalaman}

Pengalaman pedagang dapat tercermin dari lama tidaknya seseorang menekuni profesi sebagai pedagang. Orang yang berpengalaman dalam bekerja memiliki kemampuan kerja yang lebih baik dari orang yang baru saja memasuki dunia kerja, karena orang tersebut hanya belajar dari kegiatan - kegiatan dan permasalahan yang timbul dalam kerjanya. Pada penelitian ini klasifikasi pengalaman responden dapat dilihat pada tabel 6 .

Berdasarkan analisis data primer (table 6) diketahui bahwa responden rumah makan terbanyak pada kisaran pengalaman antara $\leq 2-20$ tahun ke atas, dengan total keseluruhan $93 \%$. Sedangkan responden rumah makan yang paling sedikit berada pada kisaran pengalaman 41 - 50 Tahun ke atas, dengan total keseluruhan 1 orang dengan persentase $7 \%$.

\section{Pendapatan}

Pendapatan merupakan penghasilan yang timbul dari aktivitas usaha yang biasa dikenal dengan sebutan yang berbeda seperti penjualan, penjualan jasa (fee), bunga, dividen, royalti, dan sewa. Pendapatan merupakan hal yang sangat penting, karena pendapatan itu yang menjadi obyek atas kegiatan usaha. Karena pendapatan akan menentukan maju - mundurnya suatu usaha. Oleh karena itu pewirausaha harus berusaha semaksimal mungkin untuk memperoleh 
pendapatan yang diinginkan atau diharapkan. Klasifikasi pendapatan responden rumah makan di Kec. Kota Kefamenanu dalam penelitian ini dapat dilihat pada tabel 7 .

Tabel 6. Klasifikasi pengalaman responden di Kec. Kota Kefamenanu, Tahun 2017.

\begin{tabular}{cccc}
\hline No. & Pengalaman & Jumlah $(\boldsymbol{\Sigma})$ & Persentase (\%) \\
\hline 1 & $\leq 2-20$ & 13 & 93 \\
2 & $21-30$ & 0 & 0 \\
3 & $31-40$ & 0 & 0 \\
4 & $41-50$ & 1 & 7 \\
\hline \multicolumn{5}{c}{ Total } & $\mathbf{1 4}$ & $\mathbf{1 0 0}$ \\
\hline
\end{tabular}

Sumber : Analisis Data Primer (2017)

Tabel 7. Klasifikasi pendapatan Rumah Makan di Kec. Kota Kefamenanu, Tahun 2017.

\begin{tabular}{cccc}
\hline No. & Pendapatan & Jumlah $(\Sigma)$ & Persentase (\%) \\
\hline 1 & $2.000 .000-5.999 .999$ & 8 & 57 \\
2 & $6.000 .000-10.999 .999$ & 2 & 14 \\
3 & $11.000 .000-15.999 .000$ & 3 & 21 \\
4 & $16.000 .000-20.000 .000$ & 1 & 7 \\
\hline \multicolumn{2}{c}{ Total } & $\mathbf{1 4}$ & $\mathbf{1 0 0}$ \\
\hline
\end{tabular}

Sumber : Analisis Data Primer (2017)

Berdasarkan analisis data primer (table 7) diketahui bahwa jumlah pendapatan rumah makan terbanyak, pada kisaran pendapatan antara 2.000 .000 - 5.999.999, total keseluruhan 8 rumah makan, dengan persentase $57 \%$ Sedangkan responden rumah makan yang pendapatannya paling tinggi berada pada kisaran 16.000.000 - 20.000.000, dengan total keseluruhan 1 rumah makan, persentase $(7 \%)$.

Faktor - faktor yang mempengaruhi permintaan sayuran daun oleh rumah makan di Kec. Kota Kefamenanu.

Faktor yang dijabarkan dalam bentuk variabel yakni variabel bebas $(\mathrm{X})$ yang mempengaruhi variabel terikat (Y). Dalam penelitian ini terdapat 5 (lima) variabel bebas $(\mathrm{X})$ yakni $\left(\mathrm{X}_{1}\right)$ Pengeluaran Pembelian Sayuran Daun, $\left(\mathrm{X}_{2}\right)$ Pengeluaran Pembelian Sayuran Pengganti, $\left(\mathrm{X}_{3}\right)$ Jumlah Menu Olahan, $\left(\mathrm{X}_{4}\right)$ Jumlah Tamu/Pembeli, $\left(\mathrm{X}_{5}\right)$ Jumlah Tamu Pada Event, yang mempengaruhi (Y) Jumlah Permintaan Sayuran dalam satu bulan.

$Y=219.793+4.170 X_{1}-1.080 X_{2}-5.338 X_{3}+0.033 X_{4}-0.003 X_{5} \ldots(1)$

Tabel 8. Hasil Persamaan Permintaan Sayuran Daun Oleh Rumah Makan di Kota Kefamenanu

\begin{tabular}{cccc}
\hline di Kota Kefamenanu & & & \\
\hline Variabel & Coefficient & t-Statistic & Prob. \\
\hline C & 219.793 & 134.517 & 0,141 \\
X1 & 4.170 & 0.000 & $0.013^{\mathrm{a}}$ \\
X2 & -1.080 & 0.000 & 0.752 \\
X3 & -5.338 & 29.517 & 0,861 \\
X4 & 0.033 & 0.020 & $0.142^{\mathrm{b}}$ \\
X5 & -0.003 & 0.020 & 0.889 \\
R-squared & 0,796 & & \\
Prob(F-statistic) & 0,012 & & \\
\hline
\end{tabular}

Keterangan : a dan b signifikan pada $\alpha: 0.05,0.20$.

\subsection{Interpretasi Hasil Analisis Permintaan Sayuran Daun oleh rumah} Makan di Kota Kefamenanu

1. Pengeluaran Pembelian Sayuran Daun terhadap Jumlah Permintaan Sayuran.

Pengeluaran pembelian sayuran mempunyai pengaruh positif dengan nilai 0,671 . Ini berarti jika pengeluaran pembelian sayuran daun meningkat 1 rupiah menyebabkan jumlah permintaan sayuran daun naik $0,671 \mathrm{Kg}$.

2. Pengeluaran Pembelian Sayuran Pengganti Terhadap Jumlah Permintaan Sayuran

Pengeluaran pembelian sayuran pengganti terhadap jumlah permintaan sayuran Variabel sayuran pengganti memiliki regresi -0,068. Ini berarti jika pengeluaran pembelian sayuran pengganti naik 1 rupiah menyebabkan jumlah permintaan sayuran daun turun $-0,068 \mathrm{Kg}$. Sipayung (2015) harga barang substitusi mempunyai pengaruh negatif terhadap penawaran barang yang digantikannya. Demikian juga sebaliknya bila harga ubi kayu meningkat maka penawaran kentang juga ikut menurun.

\section{Jumlah Menu Olahan terhadap Jumlah Permintaan Sayuran}

Pengaruh variabel Jumlah menu olahan terhadap jumlah permintaan sayuran daun mempunyai pengaruh negatif dengan nilai -0,047. Ini berarti jika jumlah menu olahan naik 1 menu menyebabkan jumlah permintaan sayuran daun turun $-0,047 \mathrm{Kg}$.

\section{Jumlah Tamu/Pembeli terhadap Jumlah Permintaan Sayuran.}

Jumlah tamu/pembeli terhadap jumlah permintaan sayuran mempunyai pengaruh positif dengan nilai 0,509 . Ini berarti jika jumlah tamu/pembeli naik 1 orang menyebabkan jumlah permintaan sayuran daun naik $0,509 \mathrm{Kg}$.

\section{Jumlah Tamu Pada Event terhadap Jumlah Permintaan Sayuran.} Jumlah tamu pada event terhadap jumlah permintaan sayuran Y. Sedangkan dari hasil tabel koefisien memperoleh hasil negatif dengan nilai -0,054. Ini berarti jika jumlah tamu pada event naik 1 orang menyebabkan jumlah permintaan sayuran daun turun $-0,054 \mathrm{Kg}$.

\section{Koefisien Determinasi $\left(\mathbf{R}^{2}\right)$}

Koefisien determinasi ( $R$ Square) atau sering disimbolkan dengan $\mathrm{R}^{2}$ dimaknai sebagai sumbangan pengaruh yang diberikan variabel bebas $(\mathrm{X})$ terhadap variabel terikat (Y) dalam model persentase (\%) dan tabel 8 menampilkan model kontribusi variabel bebas yang terakomodir dalam penelitian ini.

Berdasarkan tabel 8 dapat dikatakan bahwa koefisien determinasi atau Rsquare dalam model diatas memiliki nilai 0,796 yang mana kontribusi variabel bebas yang terdiri dari pengeluaran pembelian sayuran daun $\left(\mathrm{X}_{1}\right)$, pengeluaran pembelian sayuran pengganti $\left(\mathrm{X}_{2}\right)$, jumlah menu olahan $\left(\mathrm{X}_{3}\right)$, jumlah tamu/pembeli $\left(\mathrm{X}_{4}\right)$, jumlah tamu pada event $\left(\mathrm{X}_{5}\right)$ terhadap variabel terikat yaitu jumlah permintaan sayuran (Y) sebesar 79,6\% dan sisa kontribusi sebesar 20,4\% adalah model dari variabel bebas yang tidak terakomodir dalam penelitian ini.

\section{Uji Simultan atau Secara Serempak $\left(F_{\text {hitung }}\right)$}

Uji $\mathrm{F}$ adalah untuk mengetahui apakah variabel bebas dalam model persamaan permintaan sayuran daun memiliki pengaruh secara bersama-sama terhadap variabel terikat. Variabel bebas yaitu pengeluaran pembelian sayuran, pengeluaran pembelian sayuran pengganti, jumlah menu olahan, jumlah tamu, jumlah tamu pada event secara bersama berpengaruh nyata terhadap permintaan sayuran daun. Pada Tabel 8 dapat dilihat dari probabilitas F hitung 0,012 Variabel bebas berpengaruh nyata terhadap variabel terikat dengan $\alpha=5 \%$

\section{Simpulan}

Faktor-faktor yang mempengaruhi permintaan sayuran daun secara signifikan adalah pengeluaran pembelian sayuran dan jumlah tamu. Pengeluaran pembelian sayuran dan jumlah tamu memiliki pengaruh yang positif.

\section{Pustaka}

Badan Pusat Statistik.2010. Timor Tengah Utara Dalam Angka 2010. Badan Pusat Statistik. Timor Tengah Utara.

Badan Pusat Statistik.2010. Data Pendapatan Penduduk dan Pertumbuhan Ekonomi. Badan Pusat Statistik. Timor Tengah Utara.

Badan Pusat Statistik.2011. Timor Tengah Utara Dalam Angka 2011. Badan Pusat Statistik. Timor Tengah Utara.

Badan Pusat Statistik.2012. Timor Tengah Utara Dalam Angka 2012. Badan Pusat Statistik. Timor Tengah Utara.

Badan Pusat Statistik.2013. Timor Tengah Utara Dalam Angka 2013. Badan Pusat Statistik. Timor Tengah Utara.

Badan Pusat Statistik.2014. Data Perdagangan Timor Tengah Utara. Badan Pusat Statistik. Timor Tengah Utara.

Badan Pusat Statistik.2018. Timor Tengah Utara Dalam Angka 2018. Badan Pusat Statistik. Timor Tengah Utara.

Bungin, Burhan. 2008. Penelitian Kualitatif, Komunikasi, Ekonomi, Kebijakan Publik, dan Ilmu Sosial Lainnya. Jakarta: Kencana Pranada Media Grup.

Gujarati N. Damodar. 2003. Basic Econometric, Fourt Edition. New York: McGraw-Hill.

Rahadi, F., Roni Palungkum dan Asiani Budiarti. 1995. Agribisnis Tanaman Sayuran. Jakarta. Erlangga.

Sipayung, Boanerges.2015.Analisis Faktor Penawaran dan Permintaan Kentang di Provinsi Sumatera Utara. Tesis, Program Magister Agribisnis Universitas Sumatera Utara. Medan.

SPPIP Kota Kefamenanu Tahun 2012. Data Strategi Pembangunan Pemukiman dan Infrastruktur Perkotaan. Kefamenanu

Sugiyono. 2006. Metode Penelitian Kuantitatif Kualitatif dan R\&D. Bandung: Alfabeta. 